\title{
CHANGE BACK FEATURE FOR CONSUMER ACCOUNTS
}

\author{
Cheman Shaik \\ VISH Consulting Services Inc, 6242 N Hoyne Avenue, Chicago IL 60659, USA
}

\begin{abstract}
The aim of this paper is to propose a new feature called Change Back for consumer accounts, which minimizes the use of cash coins by retail consumer outlets and eliminates the need of carrying the same for banks' consumer customers. Once implemented in consumer banking applications and point-of-sale devices, the feature will minimize the wastage of coins by shoppers, commission charges incurred by retail vendors on coins, improve money retention by banks in their consumer accounts and minimize of the spread of pandemics.
\end{abstract}

Discussed in detail are how the Cash Back transaction takes place and what needs to be implemented by different parties involved in making it a success. A step-by-step flow of the transaction is pictorially described from a point-of-sale device at a retail cash counter to a bank's payment processing application.

\section{KEYWORDS}

Consumer Accounts, Point-of-Sale Devices, Change Back Feature

\section{INTRODUCTION}

Every government of the world mints cash coins to facilitate small scale, daily business transactions in their country. Cash coins are a part and parcel of our mini sale and purchase activities. Coin minting, delivery and their circulation in the market is a continuous process of economics. Government mints produce coins on a regular basis in order to meet their demand in the market. For example, the US mint produces more than 10 billion coins a year ${ }^{[1]}$

Returning money less than a basic currency unit in the form of coins to buyers is a very common practice at retail counters. Coins that a buyer takes home pools up gradually in a year into a significant amount and it goes unused or is discarded most of the times. Usually, buyers feel inconvenient to carry coins for shopping and reuse them at retail counters as it slows down the transaction process, thereby wasting valuable time. On the other hand, retail vendors incur commission charges on coins that they acquire from coin suppliers.

In advanced countries such as USA, Europe and certain Gulf countries where the basic currency units such as Dollar, Pound Sterling, Euro and Dinar have a high value, even coins carry such a value that cannot be ignored. A new feature implemented in consumer bank accounts and pointof-sale devices can solve this problem and save significant amount of money for retail vendors and their customers. Further, it improves retention of money in consumer banks that would otherwise be discarded or lost due to negligence.

As a rough estimate, on average a family carries home nearly $\$ 500$ over a year from retail shopping outlets whereas singles carry nearly $\$ 200$. These amounts are significant when pooled 
up over a year and can be effectively saved if properly credited back to their personal accounts by performing a Change Back transaction. Moreover, this will minimize the burden on Government Mints by reducing the work force required in minting various denominations of coins, cutting power consumptions of minting machines and curtailing their maintenance cost.

When a buyer tenders a currency bill at a retail shopping counter for a purchase, coins left after the transaction can be returned to the buyer's personal account, or alternatively passed to a charity depending upon the buyer's decision.

\section{LiteratURE SURVEY}

Actually, nothing has been thought of and no research has been conducted so far in regards to the Cash Back feature. It is a new feature proposed for the first time in this paper advocating its benefits for retail shoppers, banks, governments and the society. However, one aspect of the Cash Back feature, that is, making donations to charities at retail cash counters is already in practice ${ }^{[2]}$.

Certain advanced countries like United States, Australia and New Zealand made moves in the past to discontinue the production of too smaller coins such as pennies due to their higher cost of production than they are really worth ${ }^{[3]}$ but we still have all other denominations circulating around in the market.

\section{Necessity to Minimize Coin Circulation}

In the wake of the recent pandemic all over the world it is more advisable to reduce the usage of coins and minimize their circulation in the market. Coin circulation spreads the pandemic rapidly as its virus can survive on metal objects for seven days which is long enough a duration to infect all those coming in contact with them ${ }^{[4]}$.

Retails cash counters, coin kiosks, coin operated washers and dryers at laundries are the most common places where an epidemic can spread rapidly. Minimizing the usage of coins will be a proactive measure to deter the spread of epidemic.

\section{Change Back Feature}

Change Back is a feature that could be added to consumer bank accounts and point-of-sale devices in order to enable buyers to return their coins left after a transaction to their bank accounts. Fig. 1 illustrates the process of a change back transaction taking place at a retail business cash counter. 


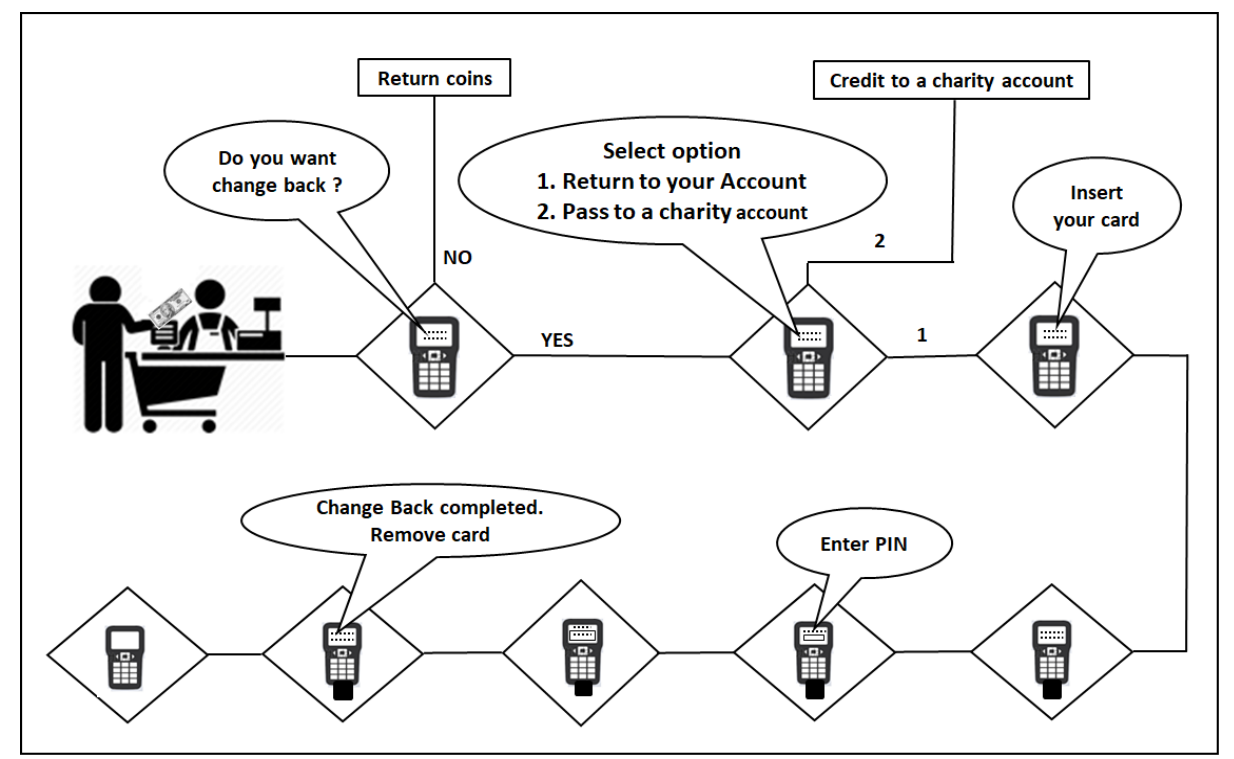

Fig. 1. A cash back transaction taking place at a retail cash counter

When a buyer tenders a currency bill at the payment counter of a store, the shop keeper would ask him if he wants to go for change back option. If the buyer opts for change back, he will be asked to select one out of the two options - return the change back to his own account or pass it to a charity account. In case the buyer goes with the first option, he will be asked to insert his credit or debit card following which he will be asked to enter his PIN ${ }^{[5]}$. Once the buyer enters his PIN, the point-of-sale device will send a request to his card provider's server to credit his account with the change amount ${ }^{[6]}$.

On the other hand, if the buyer goes for the second option, the point-of-sale device will send a request to a charity organization's card provider server which is preconfigured in the point-ofsale device. The pos device may also be preconfigured with multiple charity organizations in which case the buyer may select a charity organization of his choice.

\section{TECHNICAL IMPLEMENTATION}

The technical implementation of cash back feature is very simple without any complexities. It does not require any hardware or additional infrastructure setup by the buyer's card provider or his account holding bank. Change back transactions can be handled with the existing card provider's payment application and the bank's personal banking application. Fig. 2 and 3 illustrate transactions performing cash back to customer's bank account and charity respectively. 
International Journal of Computer Science, Engineering and Applications (IJCSEA) Vol.10, No.5/6, December 2020

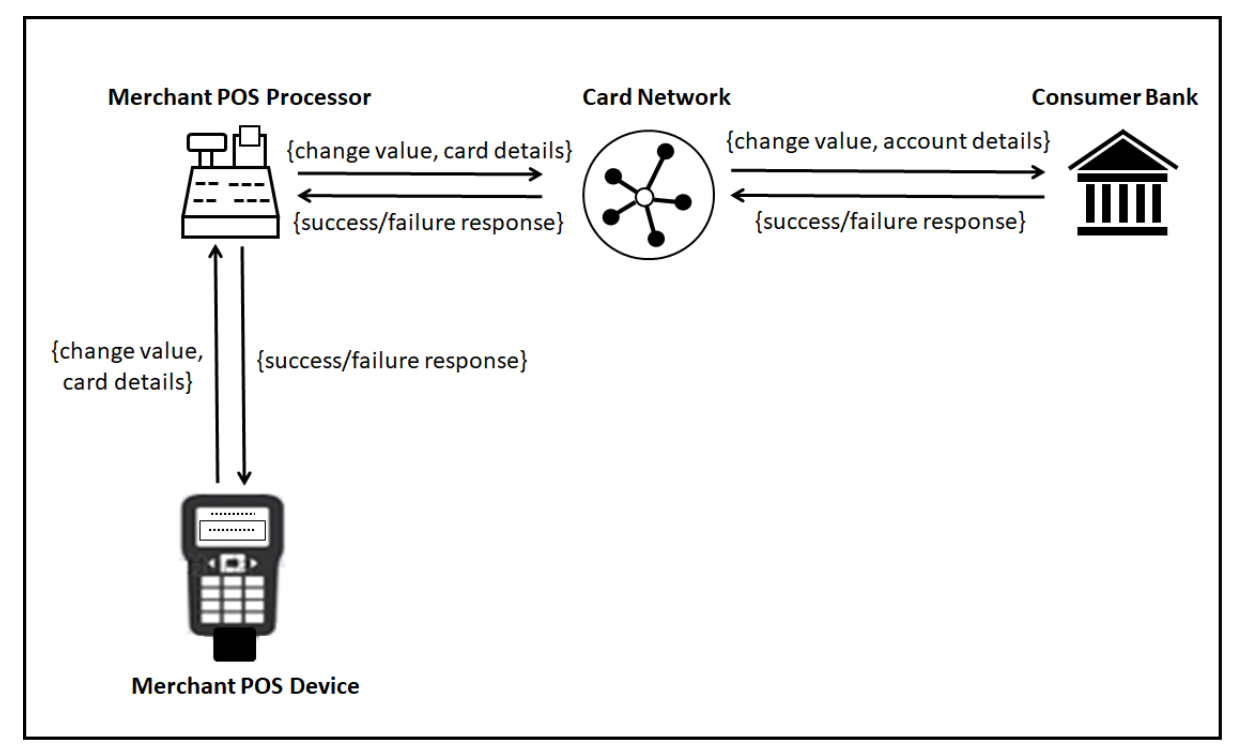

Fig. 2. A transaction performing cash back to customer's account

When a customer submitting a currency bill at a cash counter, the POS device prompts him to select one of the two options - cash back to his bank account and charity. In case the customer opts for cash back to his bank account, he will be prompted to insert his credit or debit card ${ }^{[7]}$.

Subsequently, the POS processor captures the change value left after transaction and the card details and passes the same to the cards network, where his bank and account details are retrieved. The cards network further submits the change value and customer account details to the concerned bank's application where the cash back transaction is completed by crediting the customer's account accordingly.

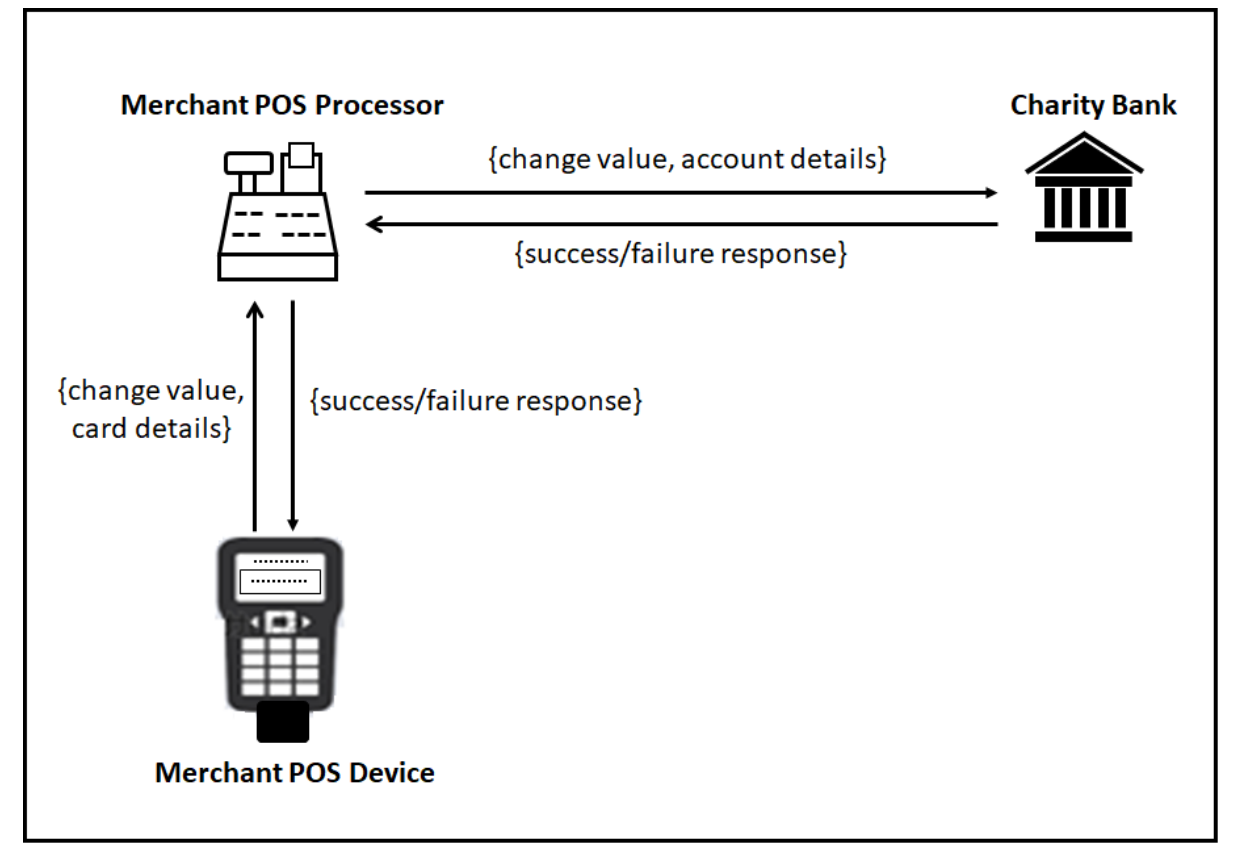

Fig. 3. A transaction performing cash back to a charity 
In case the customer opts for cash back to a charity organization, he will be prompted to select a charity from a list of available charities. Subsequently, the POS processor captures the change value left after the transaction and passes the same to the selected charity's bank application, where the charity bank retrieves the change value and credits the charity account.

\section{POS DEVICE UPGRADE}

Software of the POS device and processor that support the Change Back feature need to be upgraded to accept input from buyers and the payment counter staff. The software may be upgraded such that when the payment counter staff selects Cash Payment option on the POS monitor, the POS device will display a prompt for the buyer asking whether he wants to go for Change Back, with YES and NO buttons. When the buyer taps NO, the counter staff returns him the loose coins. If the buyer taps YES, the POS device will display two options for the buyer: Return change to your account and Return change to a charity.

When the buyer goes with the first option, the POS device will prompt him to enter his credit or debit card. Once a card is inserted, the change value and the card details are passed to a card network that will pass the information to the buyer's bank server. On the other hand, if the buyer goes with the second option, the change value and the charity organization's account details configured in the POS terminal are passed to its bank server. Alternatively, the buyer may be provided an option to select one of the multiple charity organizations configured in the POS software.

\section{Transaction Handling By CONSUmer Banks}

Consumer banks can handle change back transactions with minimal updates to their transaction handling software. POS processor of the retail vendor involved in the transaction passes the buyers card details and transaction amount, and transaction type to the cards network. A new transaction type named CHANGE-BACK may be added by the consumer bank to the list of transaction types either in their backend software code. Persisting transactions of this kind with transaction type as cash-back would be useful in grouping them in transaction reports generated for customers or the banks analytical work.

\section{FinANCial IMPACt ON BANKS}

Consumer banks incur no cost on any additional hardware or software infrastructure required to implement the new feature. They may require only nominal enhancement to their transaction processing and report generating applications.

The new feature implemented by consumer banks will improve money retention in their personal accounts which would otherwise be carried over by consumers in the form of coins.

\section{Financial Gain For Government Mints}

The burden of minting cash coins on Government Mints will be relieved significantly. Further, the minimized manpower requirements, reduced machinery maintenance cost and curtailed electricity bills will result in Government savings. Reduced metal consumption will slash demand for the metal such as copper, zinc and nickel, thereby controlling their prices in the metal market $[8]$. 


\section{RECOMMENDATIONS to POS DeViCE MANUfaCtURERS}

The main players in making the change back transactions successful are POS device manufacturers. POS device manufacturers may need to enhance their software with additional customer interaction scripts in order to enable customers at check-in counters to opt for change back transaction.

POS processors may be upgraded with additional configuration capabilities to configure charity organizations and their bank account details. The list of configured charity organizations should show up on the POS device screen when a customer opts for change back to charity. The POS processor software must be capable of maintaining their repository of charity organizations allowing addition and deletion thereof.

Once a customer opts for change back to charity option, the POS device may display some symbolic images of charity categories such as Child Education, Orphanage, Disabled and Homeless. Once a user taps one of these symbolic images, the change back amount would be transferred to one of the charity organizations configured under that category.

\section{Advantages}

- minimization of coin usage at retail outlets

- minimization of wastage of coins at home

- minimization of coin production at government mints

- improvement of savings for consumers

- improvement of money retention for banks in their customer accounts

- minimization of commission on coin trading for retailers

- minimization of metals usage

- prevention of the spread of virus-based epidemics

\section{TeChNiCAL AND Business Challenges}

- slight enhancements required for banking applications

- enhancements required for POS software

- educating consumer customers by banks

- encouraging customers at retail cash counters

- email campaigns required to popularize usage of change back feature

- initial adaption of customers to use change back feature

- initial adaption of banks, card issuers and POS manufacturers

\section{CONCluSion}

Cash coins are a part and parcel of our daily transactions at cashier desk of any retail business. It would be a good move to eliminate cash coins and phase out their production by government mints as it offers multiple benefits to shoppers, banks, charity organizations, government mints and even the entire society in terms of minimizing the spread of pandemics.

A new feature called Change Back is proposed for consumer bank accounts that will gradually reduce and eventually wipe out cash coins from the market. The proposed solution is discussed in detail explaining as to how a point-of-sale device facilitates the Cash Back transaction for a 
customer at a checkout counter of retail business and how the cards network and bank payment application process the transaction.

Implementing the cash back transaction requires point-of-sale device software to be updated accordingly and payment processing applications of banks to go for slight software enhancements. Cash Back feature is highly worth implementing for the multiple advantages it will offer to the society, despite a few challenges that the point-of-sale device manufacturers and banks will have to meet during the initial stages of implementation.

\section{REFERENCES}

[1] CoinNews.net, "U.S. Mint Produces 3.2 Billion Coins for Circulation in First Quarter 2020", https://www.coinnews.net/2020/04/23/u-s-mint-produces-3-2-billion-coins-for-circulation-in-firstquarter-2020/

[2] Brian R. Kinard, Minerva Lacal Pardo, "Cause-Related Marketing: The Effect of Checkout Charity Requests on Consumer Donation Behavior", Atlantic Marketing Journal, Vol. 6, No. 2

[3] Andrew Keinsley, "Do You Mind if I Round?: Eliminating the Penny A Structural Analysis", http://www2.ku.edu/ kuwpaper/2013Papers/201309.pdf

[4] HealthLine, "How Long Does the Coronavirus Live on Different Surfaces?", https://www.healthline.com/health/how-long-does-coronavirus-last-on-surfaces\#temperature

[5] Odysseas Papadimitriou, "How Credit Card Transaction Processing Works", https://wallethub.com/edu/cc/credit-card-transaction/25511/

[6] GAM Payments, "How Debit Card Processing Works", https://gampayments.com/how-debit-cardprocessing-works/

[7] Total Merchant Services, "Debit Cards vs Credit Cards: How Does Payment Processing Differ?", https://www.totalmerchantservices.com/blog/debit-cards-vs-credit-cards-payment-processing-differ

[8] Ducksters.com, "Money and Finance How Money is Made: Coins", https://www.ducksters.com/money/how_money_is_made_coins.php 